\title{
Jogos interpretativos e palestras: ferramentas de educação ambiental do Parque Nacional dos Campos Gerais (Paraná)
}

\author{
Interpretative games and talks: environmental education tools at Campos Gerais National Park (Paraná) \\ Jasmine Cardozo Moreira \\ Univ. Est. Ponta Grossa, Campus Central, Pr. Santos Andrade, n. 1. 84010-790 Ponta Grossa, Paraná \\ E-MAL: JASMINECARDOZO@GMAL.COM
}

Abstract: Environmental Education can integrate recreational activities, promoting the awareness of society for the conservation and protection of natural resources. This paper aims to present an interpretive game and the results of the Environmental Education Project developed in the Campos Gerais National Park - Paraná, entitled "ICMBio goes to schools: getting to know the Protected Areas". These activities aim to present the relevant characteristics of local geodiversity and biodiversity that led to the creation of this unit, seeking the support of the community for the conservation of the region. The project focuses on local schools. The methodology used included bibliographic and documentary research, questionnaires, and the game. It is concluded that the result of these actions contributes to the awareness of the students and to show the importance of the conservation of the natural heritage of the Campos Gerais National Park.

\author{
Manuscript: \\ Recebido: 28-mai-18 \\ Correções: $27-$ jun-18 \\ Aceito: 5 -ago-18
}

Citation: Moreira J.C. 2018. Jogos interpretativos e palestras: ferramentas de educação ambiental do Parque Nacional dos Campos Gerais (Paraná). Terræ Didatica, 14(4):467-476. URL: http://www. ige.unicamp.br/terraedidatica/.

Palavras-chave: Meio ambiente, jogos, áreas protegidas.

\section{Introdução e contexto do trabalho}

Diante dos problemas ambientais que surgem por meio da utilização indevida dos recursos naturais, é necessária a realização de ações que visem à sensibilização da sociedade em relação à proteção e a conservação desses recursos. Dessa forma, a Educação Ambiental (EA) apresentando diferentes metodologias, pode preencher essa lacuna, expondo temas relevantes principalmente na classe estudantil, incentivando o equilíbrio entre o homem e o meio.

Alguns Parques Nacionais vêm desenvolvendo atividades de Educação Ambiental dentro e fora das suas unidades (ICMBio \& WWF 2016, Gebauer 2014, Brasil 2015, Baumgratz et al. 2006, Maciel \& Alves 2018). As atividades são necessárias porque muitas vezes a própria comunidade do entorno desconhece a existência e o propósito da sua criação. Espera-se que por meio da EA ocorra a sensibilização tanto da comunidade como dos visitantes, para que em conjunto com o órgão gestor, possam contribuir para a conservação do seu patrimônio natural.
O Parque Nacional dos Campos Gerais (PNCG/PR) foi criado em 2006, ainda não possui regularização fundiária concluída, englobando em sua área propriedades particulares com uso agropecuário e turístico. Muitas dessas áreas que possuem o uso turístico já são visitadas pelos moradores da região há décadas, mas poucos sabem que estão dentro de uma Unidade de Conservação (UC) de proteção integral. Assim, uma das formas encontradas para se abordar o assunto com a comunidade local foi por meio de projeto que envolvesse alunos das escolas da região em atividades de educação ambiental.

Deste modo, o projeto acontece em escolas que se encontram no entorno da UC, levando à comunidade, por meio da participação no jogo e nas palestras, informações sobre a geodiversidade e biodiversidade locais. Essa ação visa aproximar a comunidade da gestão da UC, visto que a unidade existe há mais de dez anos, por meio de decreto de criação, e grande parte da comunidade ainda desconhece sua existência. 


\section{Objetivos}

O presente artigo tem como objetivo apresentar os resultados do projeto de EA desenvolvido no PNCG/PR, intitulado "ICMBio vai às escolas: conhecendo as Unidades de Conservação da natureza", no que diz respeito à aplicação de um jogo interpretativo, bem como das palestras realizadas. Para tanto, este artigo apresenta também a análise de questionários entregues antes das palestras e após a realização do jogo.

Além disso, é descrita a elaboração do jogo interpretativo sobre o PNCG/PR, criado no sentido de aproximar os alunos ao tema proposto pelo projeto e incrementar a divulgação dos aspectos da UC.

\section{Materiais, métodos e técnicas}

O Projeto realizado pelo ICMBio (Brasil, 2015) vem sendo desenvolvido desde o ano de 2012 e já envolveu 35 escolas e mais de 4000 alunos da região.

Os dados apresentados neste artigo foram coletados no segundo semestre de 2014, em 12 escolas públicas de Ensino Fundamental e Médio dos municípios de Ponta Grossa e Castro (Paraná). Nesse período foram realizadas 58 palestras, totalizando 1477 alunos. Para esses alunos foram aplicados questionários de levantamento de conhecimentos prévios, a respeito do ICMBio e da UC. Esta atividade foi direcionada para o público do Ensino Fundamental II, do sexto ao nono ano.

Assim, este artigo constitui-se em pesquisa quantitativa, sendo que a análise foi realizada visando identificar a percepção dos alunos a respeito do Parque Nacional dos Campos Gerais, das palestras realizadas e do jogo interpretativo. Os questionários utilizados possuíam perguntas fechadas, dicotômicas e de múltipla escolha, e foram adaptados de Rampel et al. (2008), que realizaram pesquisa para identificar a percepção ambiental da comunidade escolar do município de Canela (RS), no entorno da Floresta Nacional de Canela.

Para a fundamentação teórica do artigo e para a preparação das palestras, foram utilizadas pesquisas, artigos, capítulos de livro e outros estudos sobre a geodiversidade, biodiversidade e os atrativos turísticos da UC, interpretação ambiental e educação ambiental (Melo et al. 2005, Melo et al. 2007, Moreira 2014, Oliveira 2012, Baptista \& Moreira 2017, Vasconcelos 2003, Dalazoana \& Moro 2011).

Para a realização do projeto, foi estabelecido acordo de parceria com a Secretaria de Estado da
Educação do Paraná (SEED), por meio da autorização para a realização de palestras para alunos das escolas que se encontram nos municípios de Ponta Grossa, Castro e Carambeí, que integram PNCG/ PR. Também foi firmada parceria com o Laboratório de Turismo em Áreas Naturais da Universidade Estadual de Ponta Grossa (UEPG).

As palestras foram ministradas por integrantes da equipe local do ICMBio e por acadêmicos do curso de Bacharelado em Turismo da UEPG, e a preparação do conteúdo sobre a UC foi feita pelo ICMBio. Cada palestra teve a duração de 40 minutos e foi desenvolvida na própria sala de aula, em uma aula de Geografia.

Em um segundo momento, os dados apresentados são relativos ao jogo interpretativo e ao questionário respondido após a realização da atividade. Para a elaboração do jogo foram realizadas pesquisas bibliográficas (Brougère 1998, Maluf 2008, Moreira 2010), agrupando conteúdos relevantes para o desenvolvimento da atividade e contando com um ilustrador para expressar as características necessárias. O jogo foi criado exclusivamente para a utilização no projeto, visto a inexistência de materiais desse caráter abrangendo essa temática. O material foi elaborado visando desenvolver essa atividade lúdica com os alunos após as palestras, interagindo de forma mais direta para uma melhor absorção das informações.

Para a realização da avaliação da aplicação do jogo, foi escolhida uma escola do município de Ponta Grossa. Foram realizadas reuniões com o diretor e a coordenadora pedagógica da escola, para apresentar o projeto e os objetivos das atividades e foi selecionada uma turma que recebeu primeiramente a palestra. Após receber as informações sobre o ICMBio e o PNCG/PR, é que foi realizada a atividade do jogo interpretativo, em uma aula de geografia. Na utilização do jogo, inicialmente é feito o reconhecimento do tabuleiro, apresentando pormenorizadamente os aspectos ilustrados. Nessa etapa percebeu-se que os alunos já reconheciam elementos apresentados previamente na palestra, tais como espécies da flora e fauna do Parque.

Foram repassadas as regras do jogo e os grupos formados por quatro alunos cada começaram a jogar. Após a atividade, que durou cerca de uma hora, 26 alunos responderam o questionário de avaliação. Entre as dificuldades apresentadas, foi verificado que em grupos de 4 alunos em uma turma com 26 alunos, uma hora não foi suficiente para que todos os grupos pudessem participar 
do jogo. O ideal seriam turmas menores, ou dois tabuleiros por turma.

\section{Caracterização da área de estudo: Parque Nacional dos Campos Gerais (PNCG/PR)}

O PNCG/PR foi criado a partir de uma força tarefa realizada entre 2003 e 2005, após estudos para elencar áreas de interesse para conservação, principalmente da Floresta Ombrófila Mista. A criação desta UC foi motivo de amplo debate, conflitos e disputas judiciais durante o ano de 2005 , sendo finalmente decretado em março de 2006 (Moreira $\&$ Rocha 2007). A sua criação levou em conta a relevância e fragilidade ambiental do local, a geologia, geomorfologia, pedologia, vegetação natural, o uso do solo e a existência de sítios de especial interesse geoambiental e turístico, mas pode-se afirmar que a composição geológica foi a condicionante fundamental para a criação do PNCG/PR no local e formato com que foi concebido (Oliveira 2012). A UC abrange parte dos municípios de Ponta Grossa, Carambeí e Castro. Segundo o ICMBio (2012) a região foi escolhida em função dos seus elevados atributos cênicos de campos com capões, incluindo cachoeiras, furnas e espécies endêmicas. Na região também é possível encontrar cânions, corredeiras, cavernas, entre outros aspectos de beleza cênica.

A geologia da área do Parque é representada por unidades geológicas que afloram no Primeiro Planalto Paranaense, tais como o Complexo Granítico Cunhaporanga (Guimarães 2000) e o Grupo Itaiacoca (Szabó et al. 2006) e, no Segundo Planalto, unidades da Bacia do Paraná, com amplo predomínio da Formação Furnas (Assine 1999) e raras exposições da Formação Iapó (Guimarães et al. 2007, Massuqueto et al. 2009). Intrusões ligadas ao enxame de diques do Arco de Ponta Grossa, principalmente constituídas de diabásio e associadas ao Magmatismo Serra Geral (Marques \& Ernesto 2004), cortam estas unidades.

Nos arenitos da Formação Furnas estão presentes cavidades subterrâneas, tais como a Caverna da Chaminé, Sumidouro do Córrego das Fendas, Furnas Gêmeas, Caverna do Zé, entre outras (ICMBio 2012). O PNCG/PR é uma das Unidades de Conservação de Proteção Integral com maior quantidade de cavernas em rochas areníticas do país (Grupo Universitário de Pesquisas Espeleológicas 2017). São as características geológicas presentes na área do PNCG/PR que são responsáveis pela maior parte de sua atratividade turística, formados pelas fraturas da Bacia Sedimentar do Paraná e posterior erosão que permitiu o afloramento das rochas e arenitos (Melo et al. 2005) e

são as feições de relevo, a rocha e seus atributos e a ação do tempo que propiciaram as paisagens de exceção e a diversidade de flora e fauna observados nos Campos Gerais (Melo 2015, p. 68).

O Parque possui espécies vegetais como a palmeira-anã, o cacto de vila-velha, a araucária, a imbuia e o xaxim. A UC protege os últimos campos naturais do Paraná, a Floresta Ombrófila Mista, mananciais (São Jorge e Pitangui) e nascentes (bacia do Tibagi e do Ribeira). Possui também diversidade de fauna, incluindo espécies ameaçadas como a suçuarana e o lobo-guará, e sítios arqueológicos (Melo et al. 2007, Dalazoana \& Moro 2011, Almeida \& Moro 2007).

Dentro dos limites do parque encontram-se alguns dos principais atrativos turísticos naturais da cidade de Ponta Grossa, como o Buraco do Padre (Figura 1), Cachoeira da Mariquinha, Cachoeira do São Jorge, Capão da Onça, Furnas Gêmeas, Furna Grande e a área da Ponte do Rio São Jorge. Em

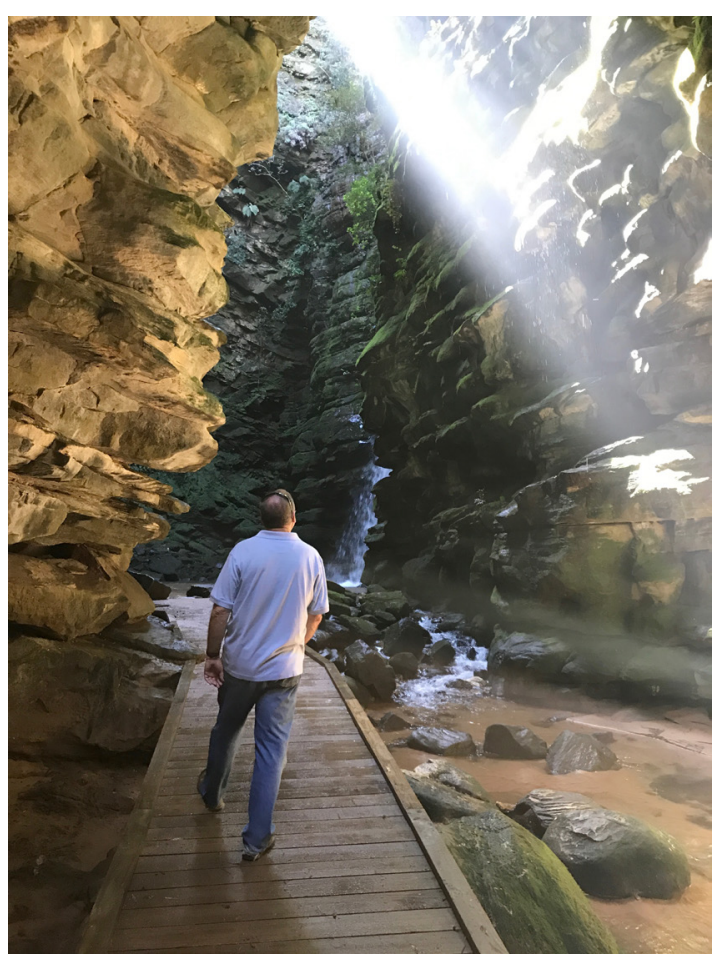

Figura 1. Buraco do Padre, furna que é um notável elemento do patrimônio geológico da região e atrativo turístico do Parque Nacional dos Campos Gerais. Fonte: Jasmine Moreira 
trabalhos realizados por Baptista e Moreira (2017), verificou-se que o PNCG/PR possui considerável potencial de agregar renda, ocupação, valorização socioambiental e cultural para as comunidades presentes em seu entorno. Pesquisas feitas por Moreira $\&$ Burns (2016) com visitantes indicaram que grande parte $(86,1 \%)$ dos entrevistados visitaram a região em viagens sem pernoite e o tempo médio de permanência foi de cerca de 3 horas, o que demonstra que boa parte dos visitantes é local.

\section{Apresentação de dados: Educação Ambiental com jogos e palestras}

A primeira definição internacional de Educação Ambiental (EA) foi adotada em 1971 pela União Internacional de Conservação da Natureza (IUCN) onde se enfatizava os aspectos ecológicos da conservação, sendo ligada à conservação dos sistemas de vida e da biodiversidade.

Com os avanços e contribuições dessa atividade, a lei no 9.795 (Brasil 1999) trouxe um conceito mais abrangente, no qual:

Entende-se por Educação Ambiental os processos por meio dos quais o indivíduo e a coletividade constroem valores sociais, conhecimentos, habilidades, atitudes e competências voltadas para a conservação do meio ambiente, bem de uso comum do povo, essencial à sadia qualidade de vida e sua sustentabilidade.

Seguindo esse pensamento, Dias (2004) afirma que a Educação Ambiental é um processo permanente no qual os indivíduos e a comunidade tomam consciência do seu meio ambiente e adquirem novos conhecimentos, valores e experiências. Já no material produzido pelo Ministério do Meio Ambiente juntamente com o ICMBio, entende-se a Educação Ambiental como "um processo eminentemente político que visa estimular a interpretação da realidade histórica e social, a ação transformadora e responsável e a intervenção consciente e intencional na realidade" (Brasil 2011 p. 26).

Deste modo, este projeto corrobora com o que é apresentado nas Diretrizes para Estratégia Nacional de Comunicação e Educação Ambiental em Unidades de Conservação, ENCEA. A Estratégia possui como objetivo geral (2011 p. 20),

Fortalecer e estimular a implementação de ações de Comunicação e Educação Ambiental em Unidades de Conservação, Corredores
Ecológicos, Mosaicos e Reservas da Biosfera, em seu entorno e nas zonas de amortecimento; promovendo a participação e o controle social nos processos de criação, implantação e gestão destes territórios, e o diálogo entre os diferentes sujeitos e instituições envolvidos com a questão no país.

Entre os objetivos específicos estão o incentivo e o incremento ao diálogo, a cooperação e o trabalho em rede entre os órgãos gestores do Sistema Nacional de Unidades de Conservação, as secretarias de educação, e as comunidades escolares. Além disso, este projeto está de acordo com a Diretriz 3 - Estímulo à inserção das Unidades de Conservação como temática no ensino formal, que sugere:

Estabelecer parcerias com universidades e com instituições de fomento à pesquisa para incentivar a realização de projetos de iniciação científica, programas de estágio e pesquisas acadêmicas no interior e entorno de UC (2011 p. 33).

Por outro lado, atividades de EA tentam promover uma mudança de comportamento da sociedade, apostando na sensibilização das pessoas para adotar uma nova postura referente à proteção dos recursos naturais e a melhoria da qualidade de vida, sendo um processo contínuo dirigido à comunidade como um todo. Para o ICMBio \& WWF (2016), a EA direcionada aos grupos sociais que convivem diretamente com a realidade das UCs, sejam os vizinhos, moradores, usuários é uma estratégia essencial para o engajamento da sociedade na tarefa de conservar as diversidades natural, histórica e cultural desses territórios. Nesse âmbito, as ações de EA em comunidades escolares no interior e no entorno de UCs tem sido uma das principais demandas de apoio encaminhadas à Coordenação de Educação Ambiental do ICMBio, a COEDU.

Farias \& Maracajá (2012) asseguram que uma alternativa para a efetividade da EA na comunidade é o desenvolvimento de ações nas escolas. Moreira (2014) destaca a necessidade do incentivo por parte do poder público na ampla participação das escolas e universidades na formulação e execução de programas e atividades vinculadas à Educação Ambiental não formal e a sensibilização da sociedade para a importância das Unidades de Conservação. Além disso, a EA pode ser um processo de formação, em que trata-se de incentivar o interesse das comunidades pela história da Terra, ao promover a inclusão do patrimônio geológico em atividades relacionadas ao meio ambiente. A proteção da geodiversidade está 
entre os objetivos de criação das UCs, bem como a interpretação ambiental, através de atividades de educação ambiental e o turismo.

A interpretação ambiental pode ser considerada parte da Educação Ambiental e facilita o conhecimento e a apreciação da natureza, ao traduzir uma linguagem técnica para os termos do público em geral, que não está acostumado com termos científicos. É uma atividade educacional que aspira revelar os significados e as relações por meio de objetos originais e meios ilustrativos, no lugar de somente comunicar a informação literal (Vasconcelos 2003).

São diversos os meios interpretativos que podem ser utilizados. Entre eles pode-se citar os painéis interpretativos, publicações impressas, audiovisuais, trilhas guiadas, os jogos e as palestras.

As palestras são consideradas meios interpretativos personalizados, devido a interação do palestrante com o público. Essa atividade pode ser desenvolvida tanto dentro de uma UC com os visitantes, como pode ser levada à comunidade. Delgado (2000) aponta que a palestra, em relação à interpretação ambiental, é uma das técnicas mais completas.

Moreira (2014) explica que uma palestra informal atinge melhor o público, podendo ser realizada com fins de orientação em campo, no centro de visitantes ou juntamente com apresentações em vídeo, dentro da sala de aula. Delgado (2000) considera que para a realização de palestras é importante que a sua duração não deva ultrapassar uma hora, o assunto a ser abordado deve ser atrativo e ameno e a condução deve ser ágil para manter o interesse.

A informação que oferece uma palestra interpretativa é tratada de maneira diferente pois o palestrante deve permitir o descobrimento e a reflexão por parte da audiência. Um exemplo da efetivação dessa atividade interpretativa é a realização de palestras em Fernando de Noronha (PE). Essa ação ocorre há mais de 20 anos diariamente e gratuitamente no Centro de Visitantes-Museu aberto da Tartaruga Marinha do Projeto Tamar/ ICMBio. As palestras seguem uma programação semanal, abordando temas como as espécies da fauna encontradas no arquipélago (tartarugas, golfinhos e tubarões, por exemplo), aspectos históricos e unidades de conservação, apresentando também noções de educação ambiental (Moreira et al. 2009).

Em parques nacionais norte-americanos há exemplos no Grand Canyon, Yellowstone, Yosemite, entre outros. As palestras são realizadas num caráter informal, assim atingem melhor o público.
São também realizadas com fins de orientação, tanto em campo como nos Centros de Visitantes, e algumas ocorrem no período noturno e ao ar livre (Moreira 2012).

Assim, para Ham (1992), as palestras são importantes no que diz respeito à transmissão de informações diretamente aos visitantes. Para uma boa palestra é necessário um tema, uma preparação sólida e entusiasmo. O mesmo autor afirma que as crianças e os jovens de hoje serão os visitantes e os guardiões dos recursos naturais de amanhã e por isso os programas escolares devem incluir conteúdos relacionados à educação e interpretação ambiental.

Programas escolares podem incluir Jogos e atividades lúdicas. O jogo sempre esteve presente no nosso cotidiano, seja na fase inicial da vida ou na fase adulta. Para Brougére (1998), o jogo corresponde a uma atividade lúdica, sendo considerado como uma atividade que imita ou simula uma parte do real. Para Maluf (2008), a questão lúdica está diretamente ligada aos jogos, brincadeiras ou a qualquer outra atividade que vise proporcionar a interação dos participantes. Ele possui a capacidade de interagir com a realidade, inserindo o participante no tema que é proposto.

Evangelista \& Soares (2011) afirmam que o lúdico na educação se torna um facilitador do ensino e contribui para a aprendizagem dos conteúdos propostos pelos professores, além disso, o lúdico parece ser um caminho interessante para uma Educação Ambiental transformadora. Assim, realizar atividades lúdicas no processo de EA acaba aproximando o participante, que começa a ter um papel ativo no aprendizado.

O participante, ao desempenhar papel funcional no aprendizado, pode ser envolvido mais ativamente em jogos, gincanas, oficinas ou qualquer outra atividade destinada aos alunos nesse processo de sensibilização. De acordo com Santana \& Rezende (2008), a atividade lúdica pode ser realizada para o aluno memorizar mais facilmente o assunto abordado, e também instigar o seu raciocínio, a reflexão, o pensamento e a construção do seu conhecimento. Essas atividades, se bem exploradas, oportunizam a interlocução de saberes, a socialização e o desenvolvimento pessoal, social e cognitivo.

Falkembach (s.d.) afirma que jogos bem concebidos e utilizados de forma adequada oferecem vantagens, entre elas: fixa os conteúdos, facilita a aprendizagem; permite a tomada de decisão e avaliações; requer participação ativa; socializa e 
estimula o trabalho de equipe; motiva, desperta a criatividade, o senso crítico, a participação, a competição sadia e o prazer de aprender.

A facilidade e a eficiência em se aprender por meio de jogos independem da idade, mas os jogos devem ser bem planejados e são os elementos do cotidiano que podem envolver os participantes no processo de educação. Guimarães et al. (2017) explicam que no caso de jogos geoeducativos, por meio de abordagens interdisciplinares e de atividades lúdicas, envolvem os elementos locais, como geodiversidade, biodiversidade, história e cultura, podendo despertar o interesse e promover o aprendizado acerca dos elementos naturais e sociais.

Moreira (2014) lembra que os jogos e atividades lúdicas podem ser realizados em Unidades de Conservação, em casa ou na escola. Entre as diversas atribuições que os jogos podem ter, está o fato de que ajudam a desenvolver um sentido de observação, o estímulo da criatividade e a oportunidade de aprender brincando. Além disso, jogos de tabuleiro e de cartas podem render bons resultados interpretativos. Nos Estados Unidos há um grande leque de opções comercializadas em lojas de Centros de Visitantes de Parques Nacionais. Um deles é o "Monopoly", jogo similar ao Banco Imobiliário, mas que utiliza no lugar dos imóveis os parques nacionais. No Brasil, tais produtos são raros, mas uma exceção é um jogo intitulado "Aventura pelos Caminhos do Brasil", no qual o objetivo é passar por parques nacionais do país, realizando atividades como rafting, canionismo, rapel e escalada.

Nos Campos Gerais, um jogo da memória contendo fotos e informações relativas ao patrimônio natural e cultural dos Campos Gerais (Moreira 2010) foi desenvolvido como resultado de um projeto de pesquisa que previa identificar riscos de degradação ambiental e propor formas de uso sustentáveis. Para Schimanski et al. (2013), essa atividade foi considerada como uma via para introduzir determinados conceitos e significados relacionados com o patrimônio, que poderiam ser trabalhados pelos professores das escolas com o auxílio dos meios interpretativos. Apesar das dificuldades apresentadas, a possibilidade de participar do projeto e discutir com as escolas permitiu um maior conhecimento sobre a região e assim percebeu-se que as atividades desenvolvidas permitiram uma aproximação mais densa com a realidade local. Projetos como esse, apesar dos obstáculos, podem auxiliar a germinar processos de politização da problemática ambiental experimentada nos Campos Gerais.

\section{Discussão e Interpretação dos resultados}

\section{Jogo Interpretativo e o Projeto de educação ambiental realizado nos municípios do Parque Nacional dos Campos Gerais}

Ao constatar que o Parque protege a biodiversidade e geodiversidade da região mas carece do apoio da comunidade, uma das ações desenvolvidas visando a conscientização da população local foi a realização de palestras sobre o que são as UCs, a função do ICMBio na região, e principalmente tratar dos aspectos do PNCG/PR. Assim, este artigo apresenta o resultado de 1477 questionários respondidos antes da realização de 58 palestras, durante o ano de 2014.

Verificou-se que em relação ao conhecimento prévio dos alunos sobre o Parque Nacional dos Campos Gerais, a grande maioria (61\%), desconhecia a existência do parque, sendo que apenas 39\% declararam que já conheciam ou já tinham ouvido falar da UC. Quando perguntados se conheciam o órgão gestor da UC, nota-se que a grande maioria, 93\%, desconhece a existência dessa Autarquia Federal, sendo reconhecido apenas por $7 \%$ dos alunos.

Em relação à visitação aos principais atrativos do PNCG/PR, as respostas indicam que $74 \%$ dos alunos já visitaram algum desses atrativos turísticos. Em relação à porcentagem dos alunos que conhecem os atrativos turísticos, as respostas indicam: Capão da Onça (27\%), seguido pelo Buraco do Padre $(26 \%)$ e a Cachoeira do São Jorge, com $16 \%$. Com $13 \%$ foi citada a Cachoeira da Mariquinha, $11 \%$ a Ponte do Rio São Jorge e 7\% as Furnas Gêmeas.

O conhecimento dessas percepções é relevante, visto que a gestão de áreas naturais tem como base uma abordagem global e sistêmica, a fim de que se compreendam as relações existentes entre os diferentes componentes dos ecossistemas, inclusive o ser humano, associado à participação das populações locais na gestão destas áreas protegidas (Jesus 1993).

Os resultados dos questionários respondidos pelos alunos antes das palestras evidenciam que é necessário realizar atividades que aproximem a comunidade da UC, principalmente ações de divulgação, visto que foram observados baixos índices de conhecimento pelos alunos que moram ao redor da UC. Além disso, cabe ressaltar que os processos de regularização fundiária da UC ainda 
estão no início e nenhuma área foi desapropriada até o momento. É notável a falta de conhecimento dos alunos sobre as questões abordadas, mostrando a importância de levar informações sobre o PNCG/ PR para a sala de aula, visto que muitos alunos já visitaram os atrativos turísticos da região, mas desconhecem que esses se encontram dentro de uma Unidade de Conservação. Com isso, observou-se que levar informações sobre o contexto local para a comunidade é uma forma de divulgar e sensibilizar os mesmos sobre a importância da conservação e a proteção do patrimônio e recursos ambientais ali existentes.

Visando complementar as palestras, foi criado um Jogo Interpretativo, direcionado ao público de 11 e 12 anos, o qual é aplicado após a realização das palestras. É um jogo de tabuleiro em forma de trilha denominado "Conhecendo o Parque Nacional dos Campos Gerais".

O tabuleiro é um tapete de $2 \times 3$ metros, produzido em lona colorida, onde os próprios alunos são as peças e fazem a movimentação. A ilustração retrata o Parque e os desenhos foram criados por um desenhista profissional, exclusivamente para o tabuleiro. Estão representados o bugio, tamanduá, lobo-guará, suçuarana, curicaca, gralha-azul, araucária, bromélia, entre outros. Representando os elementos da geodiversidade, há uma cachoeira (Fig. 2).

O tabuleiro é composto por números que indicam ações positivas e negativas do visitante, ligadas às temáticas conforme as cores: água (casa azul), fauna (casa laranja), flora (casa verde), atrativos turísticos (casa roxa) e explicações sobre o órgão gestor da UC (casa vermelha). As casas amarelas, marcadas com " ? " indicam uma ação do turista sustentável e as casas pretas não possuem nenhum comando, sendo apenas um ponto de parada.

Para cada cor das casas disponíveis no tabuleiro, existem duas situações: carta ação (ações positivas/ avançar) e carta conflito (ações negativas/recuar). $\mathrm{Na}$ frente de cada carta há uma foto e na parte de trás a explicação da carta e o comando a seguir. Quando parar em determinada cor, o participante deve retirar a carta "ação" ou "conflito" da mesma cor da casa onde parou. Há 7 cartas conflitos, 16 cartas de ações positivas e 6 cartas "?".

Conforme o número no tabuleiro, verifica-se o número na cartela de frases e a instrução é lida. Algumas das frases que integram o jogo são:

- "O Parque Nacional dos Campos Gerais é uma Unidade de Conservação administrada pelo
ICMBio e que está em processo de implementação. Você apoia essa iniciativa, pois sabe da importância de preservar esse rico ecossistema. Retire uma carta ação."

- "Você cortou a mata nativa do parque. Além de impactar a vegetação, você pode estar prejudicando o habitat de diferentes espécies. Retire uma carta conflito."

- "Você e seus amigos foram até um dos atrativos do parque e levaram sacolas para trazer o lixo para casa. Vocês entendem que a conservação desse lugar também depende das suas atitudes. Retire uma carta ação.”

- "A água é de fundamental importância para a vida de todas as espécies. Você entende que não deve desperdiçar e nem poluir esse recurso. Retire uma carta ação".

Ao retirar uma carta ação, uma das frases encontradas é:
"O cacto bola é uma planta endêmica dos Cam- pos Gerais, isto é, só ocorre aqui. Está ameaçado de extinção e isso está ocorrendo por que mui- tas pessoas os coletam e levam para casa. Você encontrou um na trilha e o deixou no lugar. Parabéns, continue preservando essa espécie. Avance duas casas".

E um exemplo de uma das cartas conflito é

"O Salto São Jorge possui cerca de 35 metros de altura e diversas quedas d'agua formando cascatas e piscinas naturais. Alguns visitantes não respeitam o ambiente natural, deixando lixo nas trilhas e tirando plantas do local. Volte 3 casas."

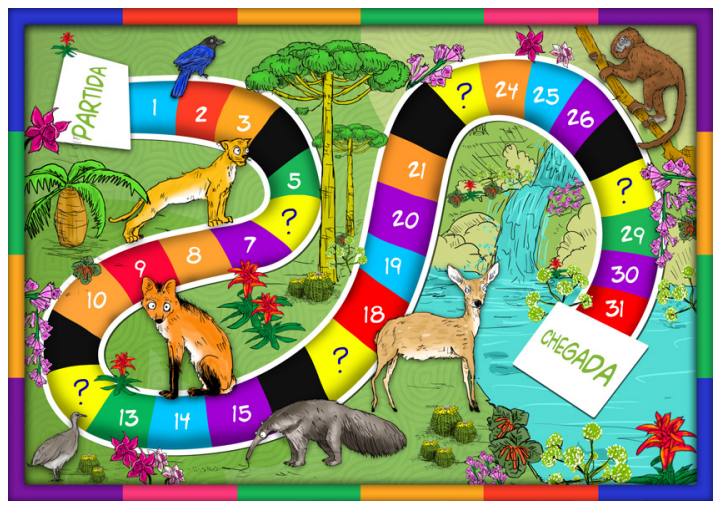

Figura 2. Jogo interpretativo "Conhecendo o Parque Nacional dos Campos Gerais". Os desenhos representam a geodiversidade e biodiversidade do Parque Nacional 
O jogo vem acompanhado de um livreto de regras, que traz também uma breve explicação sobre o Parque, aspectos da geodiversidade e biodiversidade e as referências utilizadas no desenvolvimento da atividade.

Após a realização do jogo, foi aplicado um questionário com os participantes. As respostas mostram que em relação ao Projeto, o que mais chamou a atenção para 55\% dos alunos foi o jogo e para $45 \%$ a palestra.

Em uma escala de 1 a 10, em relação ao nível de importância que os alunos creditaram para a atividade, o nível 10 foi selecionado por $70 \%$ dos alunos, e os níveis oito e nove ficaram empatados, sendo escolhidos por $15 \%$ dos respondentes. Os outros níveis não foram citados, consolidando a relevância da atividade desenvolvida. Também utilizando uma escala de 10 pontos, foi solicitado aos alunos que marcassem quanto eles julgaram ter entendido sobre o assunto abordado, sendo selecionado por $35 \%$ a escala dez, $30 \%$ a escala oito, $25 \%$ a escala nove e $10 \%$ a escala sete. O resultado mostra que a atividade resultou positivamente na disseminação das informações por meio da palestra e do jogo interpretativo, alcançando os alunos como o esperado.

Saber a percepção dos alunos em relação a efetividade da ação educativa contribui diretamente para o aperfeiçoamento da mesma, visando alcançar cada vez mais os alunos por meio de metodologias distintas. Deste modo, verificou-se que 95\% dos alunos consideraram a atividade interessante, informativa e educativa, e apenas $5 \%$ responderam que a atividade poderia ser melhorada (Fig. 3).

Ao serem questionados sobre o design do jogo, todos os alunos selecionaram que ele é atraente. $\mathrm{O}$ design foi a primeira impressão que os alunos tiveram do jogo, sendo fator primordial para aceitação dos alunos em relação a atividade.

Questionados se o jogo era de fácil entendimento, 95\% dos entrevistados responderam que sim e apenas $5 \%$ que não. Esse resultado evidencia a importância do meio interpretativo ser elaborado de acordo com a faixa etária dos envolvidos, facilitando o entendimento por meio de uma linguagem simples. Quando perguntado se as informações do jogo foram suficientes para conhecer melhor o Parque, novamente 95\% selecionaram que sim, e apenas $5 \%$ que não.

Também foi perguntado se o jogo contribuiu para a compreensão dos aspectos positivos e negativos que podem ocorrer durante a visitação, e todos

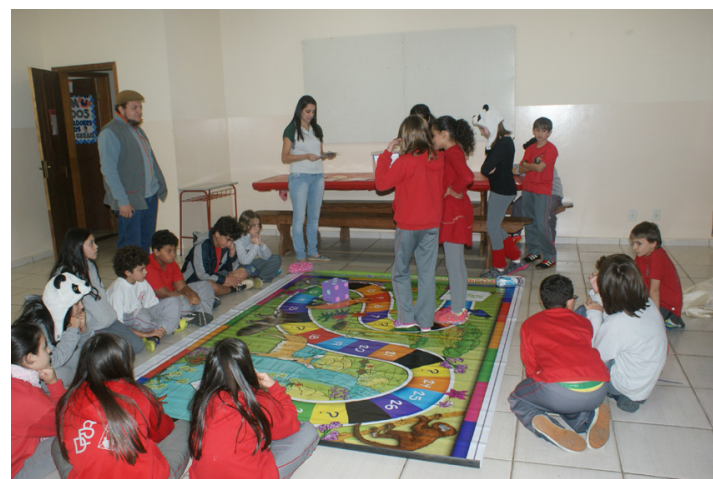

Figura 3. Realização da atividade do jogo interpretativo, após a palestra sobre o Parque Nacional dos Campos Gerais

os alunos selecionaram que sim. O conteúdo é fator essencial para que o meio interpretativo resulte na sensibilização dos envolvidos, nesse caso o repasse de informações sobre os aspectos positivos e negativos da visitação ao PNCG/PR contribuiu para tal fator. Em outra questão, todos os alunos consideraram que a atividade pode influenciar o seu modo de agir durante uma visita ao Parque, pois agora estão cientes da fragilidade dos recursos naturais existentes e a necessidade de proteção e conservação desses recursos.

Por último, foi solicitado aos alunos que deixassem sugestões sobre o jogo, apontando questões positivas e negativas. Para $70 \%$ dos envolvidos não é preciso mudar nada, para $15 \%$ o jogo poderia ser mais rápido, para $10 \%$ o jogo poderia ter mais opções de cartas e 5\% sugeriram diminuir os textos das cartas.

Em geral, a atividade foi realizada de forma satisfatória e proveitosa, visto que conforme os resultados apresentados, as informações foram transmitidas aos alunos, tanto por meio da palestra como pelo jogo, evidenciando a efetividade de ambos.

\section{Considerações Finais}

A Educação Ambiental transmite, informa, e dissemina informações que contribuem para a sensibilização dos sujeitos. Alguns Parques Nacionais brasileiros realizam atividades de EA como meio de divulgação e de conciliar a visitação com a conservação dos seus recursos naturais. A partir disso, mostra-se que cada vez mais ações informativas e interpretativas são fatores que podem também acarretar benefícios para a atividade turística.

Com a criação do Parque Nacional dos Campos Gerais em 2006, novos desafios surgiram, sendo um

\begin{tabular}{c|c|c|c|c|c|}
\hline (C) Terrae Didat. & Campinas, SP & v.14 & n.4 & p. $467-476$ & out./dez. 2018 \\
\hline
\end{tabular}


deles o envolvimento da comunidade. Para tanto, ações de comunicação e de Educação Ambiental tornam-se necessárias, ao propiciar informação e na promoção de ações educativas.

Assim, envolver alunos das escolas da região em atividades de Educação Ambiental que tratassem sobre o PNCG/PR foi uma das ações realizadas. Após a realização das atividades, foram coletados dados através de questionários e os resultados apresentados podem ser considerados positivos, ao demonstrar que as palestras e jogos permitem que os alunos tenham maior conhecimento sobre o parque, envolvendo-os no processo de aprendizado.

A criação do jogo interpretativo pode ser considerada uma oportunidade de desenvolvimento de novas metodologias interpretativas para abordar o tema Parque Nacional dos Campos Gerais, pois aprender brincando auxilia na assimilação do conteúdo sobre a Unidade de Conservação. Esse jogo pode ser usado como modelo para outras áreas protegidas brasileiras, bastando para isso adaptar o tabuleiro e as cartas utilizadas.

Por fim, percebe-se que este projeto de Educação Ambiental vem atingindo os seus objetivos, ao divulgar a existência do PNCG/PR e sensibilizar os alunos sobre a importância da proteção dos recursos naturais existentes na unidade. Entende-se que esse é um processo contínuo, no qual com base na divulgação e informação sobre a UC é possível iniciar uma mudança de comportamento na sociedade.

\section{Referências}

Almeida C.G., Moro R.S. 2007. Análise da cobertura florestal no Parque Nacional dos Campos Gerais, Paraná, como subsídio ao seu plano de manejo. Terr@Plural. 1(1):115-122. URL: http://www. revistas2.uepg.br/index.php/tp/article/viewFile/1146/856. Acesso 20.05.2015.

Assine M.L. 1999. Fácies, icnofósseis, paleocorrentes e sistemas deposicionais da Formação Furnas no flanco sudeste da Bacia do Paraná. Rev. Bras. Geoc., 29(3):357-370.

Baptista L., Moreira J.C. 2017. Ecoturismo de base comunitária no Parque Nacional dos Campos Gerais, PR: a ótica das comunidades de entorno. Pasos, Rev. Turismo y Patrimonio Cultural 15:195-210.

Baumgratz N.D.P, Pereira, R.F.P, Alves, M.P. 2016. Educação Ambiental em uma Unidade de Conservação: A visão de docentes de escolas públicas do sul fluminense. Revista Ciências EIdeias, 7(2):105-136. URL: http://revistascientificas.ifrj.edu.br:8080/revista/index.php/reci/article/view/412/392. Acesso 24.04.2017.

Brasil. 1999. Lei no 9.795 de 27 de abril de 1999. URL: http://www.planalto.gov.br/ccivil_03/leis/19795. htm. Acesso 05.02.2015.
Brasil. 2011. Diretrizes para Estratégia Nacional de Comunicação e Educacão Ambiental em Unidades de Conservação. Brasília: Min. Meio Ambiente, ICMBio. 48p. URL: http://www.icmbio.gov.br/portal/images/stories/comunicacao/publicacao_encea.pdf. Acesso 10.07.2018.

Brasil. 2015. Conflitos: estratégias de enfrentamento e medição. Série Educação Ambiental e Comunicação em Unidades de Conservação. Caderno 4. Brasília: Min. Meio Ambiente/ICMBio. 66p.

Brougère G. 1998. Jogo e Educação. Porto Alegre: Artes Médicas. 224p.

Dalazoana K., Moro R.S. 2011. Riqueza específica em áreas de campo nativo impactadas por visitação turística e pastejo no Parque Nacional dos Campos Gerais, PR. In: Revista Floresta, 41(2):387-396. URL: http://ojs.c3sl.ufpr.br/ojs/index.php/floresta/ article/viewFile/22762/15023. Acesso 06.05.2015.

Delgado J. A. 2000. Interpretação ambiental como instrumento para o ecoturismo. In: Serrano C. orgs. 2000. A educação pelas pedras - ecoturismo e educação ambiental. São Paulo: Chronos. p. 155-169.

Dias G. F. 2004. Educação Ambiental: princípios e práticas. 9a ed. São Paulo: Gaia. 541p.

Evangelista L. M., Soares M. H. F. B. 2011. Atividades lúdicas no desenvolvimento da educação ambiental. In: Simpósio de Educação Ambiental e Transdiciplinaridade, II SAET, Goiânia. Anais..., Goiânia. URL: $\quad$ https://nupeat.iesa.ufg.br/up/52/o/45_ Atividade_1_dicas.pdf Acesso 07.04.2015.

Farias M. F., Maracajá K. F. 2012. Necessidade de educação ambiental no turismo: um estudo realizado na Pousada Gargalheiras na cidade de Acari. In: Caderno Virtual do Turismo, 12(2):116-136. URL: $<$ http://migre.me/mhqXm> Acesso 03.06.2014.

Falkembach G.A.M. s.d. O lúdico e os jogos educacionais. URL: http://penta3.ufrgs.br/midiasedu/modulo13/etapa1/leituras/arquivos/Leitura_1.pdf. Acesso 30.03 .2018 .

Gebauer I.C.L. 2014. Educação ambiental em eco-trilha do Parque Nacional do Iguaçu. Revista Eletronica do Mestrado em Educação Ambiental. v.esp.:318-330. URL: https://periodicos.furg.br/remea/article/ view/4453 Acesso 10.02.2018.

Grupo Universitário de Pesquisas Espeleológicas. 2017. Cavernas: Parque Nacional dos Campos Gerais, Ponta Grossa (PR). Ponta Grossa: Radial. No. 1, 40p.

Guimarães G.B. 2000. As rochas granitóides do Complexo Granítico Cunhaporanga, Paraná: aspectos geológicos, geofísicos, geoquímicos e mineralógicos. São Paulo: Instituto de Geociências, Univ. São Paulo. 230 p. (Tese Dout.).

Guimarães G.B., Melo M.S., Giannini P.C.F., Melek P.R. 2007. Geologia dos Campos Gerais. In: Melo M.S, Moro R.S., Guimarães G.B. eds 2007. Patrimônio natural dos Campos Gerais do Paraná. Ponta Grossa: Ed. UEPG. p.23-32.

Guimarães T.O., Mariano G., Sá A.A. 2017. Jogos "geoeducativos" como subsídio à Geoconservação no litoral sul de Pernambuco (NE Brasil): uma proposta. Terrae Didatica, 13(1):30-42. URL: http://www.ige.unicamp. br/terraedidatica/. Acesso 10.02.2018.

ICMBio \& WWF. 2016. Educação ambiental em Unidades 
de Conservação: ações voltadas para comunidades escolares no contexto da gestão pública da biodiversidade. Brasília: ICMBio / MMA / WWF. 66p. URL: http:/www. icmbio.gov.br/portal/images/stories/comunicacao/ publicacoes/publicacoes-diversas/DCOM_ICMBio_educacao_ambiental_em_unidades_de_conservacao.pdf. Ācesso 15.04.2018.

ICMBio. 2012. Termo de referência - Projeto de Pesquisa para Elaboração de Estudos Prioritários de Uso Público para o Parque Nacional dos Campos Gerais- PR, como Ferramenta para a Gestão e Subsídios para o Planejamento. Ponta Grossa: ICMBio. 13p.

Ham S. 1992. Interpretacion ambiental: una guia pratica para gente com grandes ideas y presupuestos pequenos. Colorado: North. Am. Press. 437p.

Jesus T.P. 1993. Caracterização perceptiva da Estação Ecológica de Jataí (Luiz Antônio, SP) por diferentes grupos sócio-culturais de interação. São Carlos: Univ. Fed. São Carlos. 378 p. (Tese Dout.).

Maciel G.G, Alves D. 2018. Educação Ambiental no Parque Nacional da Tijuca: Diálogo entre a política pública e a sociedade. O social em questão. 40 (1):135-160. URL: http://osocialemquestao.ser. puc-rio.br/media/OSQ_40_art_6_Maciel_Alves. pdf. Acesso 22.04.2018.

Maluf A.C.M. 2008. Atividades Lúdicas para Educação Infantil: Conceitos, orientações e práticas. Rio de Janeiro: Vozes. 69p.

Marques L.S., Ernesto M. 2004. O Magmatismo Toleítico da Bacia do Paraná. In: Mantesso-Neto V., Bartorelli A., Carneiro C.D.R., Brito-Neves B.B. eds. 2004. Geologia do continente Sul-Americano: evolução da obra de Fernando Flavio Marques de Almeida. São Paulo: Beca. p. 245-264.

Massuqueto L.P., Melo M.S., Guimarães G.B., Lopes M.C. 2009. Cachoeira de Santa Bárbara no Rio São Jorge, PR: bela paisagem realça a importante contato do embasamento com rochas glaciogênicas siluro-ordovicianas. In: Winge M., Schobbenhaus C., Souza C.R.G. Fernandes A.C.S., Berbert-Born M., Queiroz E.T. eds. Sítios Geológicos e Paleontológicos do Brasil. URL: http://sigep.cprm.gov.br/sitio047/sitio047.pdf. Acesso 10.07.2018.

Melo M.S., Lopes M.C., Boska M.A. 2005. Furna do Buraco do Padre, Formação Furnas, PR: Feições de erosão subterrânea em arenitos devonianos da Bacia do Paraná. In: Winge M., Schobbenhaus C., Berbert-Born M., Queiroz E.T., Campos D.A., Souza C.R.G., Fernandes A.C.S. eds. Sítios Geológicos e Paleontológicos do Brasil. Brasília, DF. URL: http://sigep.cprm.gov.br/sitio110/sitio110_impresso.pdf. Acesso 07.12.2016.

Melo M.S, Moro R.S., Guimarães G.B. 2007. Patrimônio natural dos Campos Gerais do Paraná. Ponta Grossa: Ed. UEPG. 227p.

Melo M.S. 2015. O Parque Nacional dos Campos Gerais e a Educação para a Sustentabilidade. In: Semin. Pesq. Parque Nacional dos Campos Gerais, e da Reserva Biológica das Araucárias. Anais..., Ponta Grossa. URL: http://www.icmbio.gov.br/ portal/images/stories/oquefazemos/pesquisas/ dcom_anais_1_seminario_de_pesquisa_do_parna_dos-campos_orais_rebio_das_araucarias.pdf. Acesso 10.10.2017.

Moreira J.C., Robles R. A., Bellini C. 2009. As palestras como meio interpretativo: estudo de caso com palestrantes em Fernando de Noronha, PE. Rev. Bras. Ecoturismo, 2:322. URL: http://www. physis.org.br/ rbecotur/artigos/completo5.pdf. Acesso 5.05.2015.

Moreira J.C. 2010. A Elaboração de um Jogo da Memória como meio interpretativo para a região de Piraí da Serra. In: Simp. Pesq. Pós-Graduação, 3, 2010, Ponta Grossa. Anais..., Ponta Grossa. UEPG. URL: https://www.academia.edu/472927/a_elaboração_de_um_jogo_da_memória_como_meio_ interpretativo_para_a_região_de_piraí_da_serra_-_pr. Acesso 10.02.20 17

Moreira J.C. 2012. Interpretação ambiental, aspectos geológicos e geomorfológicos. Boletim de Geografia (UEM), 30:87-98.

Moreira J.C. 2014. Geoturismo e Interpretação Ambiental. Ponta Grossa: Ed. UEPG. 153p.

Moreira J.C., Rocha C.H. 2007. Unidades de Conservação dos Campos Gerais. In: Melo M.S., Moro R.S., Guimarães G.B. eds. 2007. Patrimônio Natural dos Campos Gerais do Paraná. Ponta Grossa: Ed. UEPG. p. 201-212.

Moreira J.C., Burns R.C. 2016. Parque Nacional dos Campos Gerais: Turismo, manejo de uso público e a percepção do visitante. Semin. Pesq. Parque Nacional dos Campos Gerais, e da Reserva Biológica das Araucárias. Anais..., Ponta Grossa. URL: http://www.icmbio.gov.br/portal/images/stories/ oquefazemos/pesquisas/dcom_anais_1_seminario_de_pesquisa_do_parna_dos-campos_on gerais rebio_das_araucarias.pdf. Acesso 10.10.2017.

Oliveira E.A. 2012. O Parque Nacional dos Campos Gerais: Processo de Criação, Caracterização Ambiental E Proposta De Priorização De Áreas Para Regularização Fundiária. Curitiba: UFPR. 294p. (Tese Dout.).

Rampel C., Muller C.C., Clebsch C.C., Dallarosa J., Rodrigues M.S., Coronas M.V., Rodrigues G.G., Guerra T., Hartz S.M. 2008. Percepção Ambiental da Comunidade Escolar Municipal sobre a Floresta Nacional de Canela, RS. Porto Alegre. Rev. Bras. Bioc., 6(2):141-147. URL: http://www. ufrgs.br/seerbio/ojs/index.php/rbb/article/viewFile/938/784. Acesso 03.06.2014.

Santana E.M. de, Rezende D.B. 2008. A influência de jogos e atividades lúdicas no ensino e aprendizagem de Química. In: Enc. Nac. Pesq. Educ. Ciências. 6, Rio de Janeiro. Anais... Rio de Janeiro. ANPEC. URL: http://www.nutes.ufrj.br/abrapec/ vienpec/CR2/p467.pdf. Acesso 11.03.2012.

Schimanski E., Moreira J.C., Moro P.R. 2013. A importância da educação ambiental no processo de defesa do patrimônio natural e cultural: o caso de Piraí da Serra, Paraná, Brasil. Revista Configurações. 11:113-127.

Szabó G.A.J., Andrade F.R.D., Guimarães G.B., Carvalho F.M.S., Moya F.A. 2006. As jazidas de talco no contexto da história metamórfica dos metadolomitos do Grupo Itaiacoca, PR. Geologia USP, Série Científica, 5(2):13-31. URL: http://www. revistas.usp.br/guspsc/article/view/27409. Acesso 10.07.2018.

Vasconcelos J.M.O. 2003. Interpretação ambiental. In: Mitraud S. org. 2003. Manual de ecoturismo de base comunitária. Brasília: WWF Brasil. p. 261-294. 